DOI: $10.17516 / 1997-1397-2021-14-5-632-637$

УДК 533.951; 550.385

\title{
Modeling of Anisotropy Dynamics of the Proton Pitch Angle Distribution in the Earth's Magnetosphere
}

\author{
Sergei V.Smolin* \\ Siberian Federal University \\ Krasnoyarsk, Russian Federation
}

Received 18.03.2021, received in revised form 10.05.2021, accepted 26.05.2021

\begin{abstract}
Last years the attention to research of anisotropy of the charged particle pitch angle distribution has considerably increased. Therefore for research of anisotropy dynamics of the proton pitch angle distribution is used the two-dimensional Phenomenological Model of the Ring Current (PheMRC 2-D), which includes the radial and pitch angle diffusions with consideration of losses due to wave-particle interactions. Experimental data are collected on the Polar/MICS satellite during the magnetic storm on October 21-22, 1999. Solving the non-stationary two-dimensional equation of pitch angle and radial diffusions, numerically was determined the proton pitch angle distribution anisotropy index (or parameter of the proton pitch angle distribution) for the pitch angle of 90 degrees during the magnetic storm, when the geomagnetic activity $K p$-index changed from 2 in the beginning of a storm up to $7+$ in the end of a storm. Dependence of the perpendicular proton pitch angle distribution anisotropy index with energy $E=90 \mathrm{keV}$ during the different moments of time from the McIlwain parameter $L(2.26<L<6.6)$ is received. It is certain at a quantitative level for the magnetic storm on October 21-22, 1999, when and where on the nightside of the Earth's magnetosphere (MLT $=2300$ ) to increase in the geomagnetic activity $K p$-index there is a transition from normal (pancake) proton pitch angle distributions to butterfly proton pitch angle distributions. That has allowed to determine unequivocally and precisely the anisotropy dynamics of the proton pitch angle distribution in the given concrete case. It is shown, that with increase of the geomagnetic activity $K p$-index the boundary of isotropic proton pitch angle distribution comes nearer to the Earth, reaching $L \approx 3.6$ at $K p=7+$.
\end{abstract}

Keywords: magnetosphere, pitch angle distribution, anisotropy, data of the Polar/MICS satellite, proton flux.

Citation: S.V.Smolin, Modeling of Anisotropy Dynamics of the Proton Pitch Angle Distribution in the Earth's Magnetosphere, J. Sib. Fed. Univ. Math. Phys., 2021, 14(5), 632-637.

DOI: 10.17516/1997-1397-2021-14-5-632-637.

\section{Introduction}

The literature on charged particle pitch angle distributions and an anisotropy of the pitch angle distributions is enough extensive. For example, modeling the pitch angle distribution on the dayside of the Earth's magnetosphere was considered in [1], and on the nightside of the magnetosphere - in [2]. In work [3] it has been offered two-dimensional Phenomenological Model of Ring Current dynamics in the Earth's magnetosphere (PheMRC 2-D). In these three works the non-stationary equation of pitch angle and radial diffusions numerically was solved in a range of pitch angles from $0^{\circ}$ up to $180^{\circ}$. In [4] has been presented the statistical analysis of pitch angle distribution of radiation belt energetic electrons near the geostationary orbit: CRRES observations with definition of an pitch angle distribution anisotropy index. A survey of the anisotropy of the outer electron radiation belt during high-speed-stream-driven storms is presented in [5].

*smolinsv@inbox.ru

(C) Siberian Federal University. All rights reserved 
An empirical model of pitch angle distributions for energetic electrons (REPAD) in the Earth's outer radiation belt has been offered in [6]. In [7] it is in detail considered statistically measuring the amount of pitch angle scattering that energetic electrons undergo as they drift across the plasmaspheric drainage plume at geosynchronous orbit. The proton and electron radiation belts at geosynchronous orbit: Statistics and behavior during high-speed stream-driven storms are presented in [8]. In [9] it is certain the inner magnetosphere ion composition and local time distribution over a solar cycle with 2001 on 2013 with the indication of an anisotropy index. And in [10] other an empirical model of radiation belt electron pitch angle distributions based on Van Allen probes measurements with examples of different typical pitch angle distributions is offered.

From the review for last years it is visible, that statistical and empirical models an charged particle pitch angle distribution anisotropy are, and the mathematical models based on the physics and describing an charged particle pitch angle distribution anisotropy index, possibly, no.

The purpose of the given work is more exact quantitative research of anisotropy dynamics of the proton pitch angle distribution during the magnetic storm in the Earth's magnetosphere. Therefore it was used the two-dimensional Phenomenological Model of the Ring Current (PheMRC 2-D) [3], based on the physics and describing the perpendicular proton pitch angle distribution anisotropy index depending from the McIlwain parameter $L$ and the geomagnetic activity $K p$-index.

\section{The mathematical model}

The offered model, PheMRC 2-D, is based on the general two-dimensional Fokker-Planck equation for phase space density, which describes the radial and pitch angle diffusions and losses due to charge exchange and wave-particle interactions. It can be expressed by the following equation [3]

$$
\begin{aligned}
\frac{\partial f}{\partial t}= & L^{2} \frac{\partial}{\partial L}\left(L^{-2} D_{L L} \frac{\partial f}{\partial L}\right)+\frac{1}{\sin \alpha} \frac{\partial}{\partial \alpha}\left(D_{\alpha \alpha} \sin \alpha \frac{\partial f}{\partial \alpha}+\sin \alpha \frac{d \alpha}{d t} f\right)- \\
& -\lambda \cdot f-\frac{f}{T_{w p}}+f S_{\perp} \sin ^{2} \alpha .
\end{aligned}
$$

Here, $f$ is the phase space density (or distribution function); $t$ is the time; $L$ is the McIlwain parameter; $\alpha$ is the local pitch angle; $D_{L L}$ is the radial diffusion coefficient; $D_{\alpha \alpha}$ is the pitch angle diffusion coefficient; $d \alpha / d t$ is the pitch angle velocity; $\lambda$ is the rate of loss due to proton neutralization by exchange of charges; $T_{w p}$ is the lifetime due to wave-particle interactions; $S_{\perp}$ is the perpendicular coefficient of the particle source function $\left(\alpha=90^{\circ}\right)$.

Equation (1) describes the radial diffusion in the "conventional" space with losses due to charge exchange and the pitch angle diffusion in the velocity space with losses due to the wave-particle interactions. Therefore, a corresponding diffusion coefficient in the velocity space (namely, the pitch angle diffusion coefficient) is needed. The loss function is conditioned by the fall of charged particles in the so-called "loss cone" as a result of wave-particle interactions. The particle source function can be related, for example, to charged particles that move from the tail of the magnetosphere toward the Earth when affected by magnetospheric convection.

Equation (1) is a non-stationary, two-dimensional, second-order, partial differential equation. Its solution should be sought as a function of $L, \alpha$, and $t$. We use this solution to determine the evolution of the pitch angle distribution of the Earth's ring current protons and to find the perpendicular $\left(\alpha=90^{\circ}\right)$ proton pitch angle distribution anisotropy index as a function of the McIlwain parameter $L$ during a given magnetic storm. 
The initial and boundary conditions are given for the following ranges of the McIlwain parameter $L$ and pitch angle $\alpha: 2.26 \leqslant L \leqslant 6.6,0^{\circ} \leqslant \alpha \leqslant 180^{\circ}$. We also use the relationship between the differential particle flux $j$ and the phase space density $f: j=2 m E f$. In detail in [3].

Thus, non-stationary two-dimensional partial differential equation (1) is solved numerically by a finite-element projection method with initial and variable boundary conditions.

\section{Results of calculations}

Next, we study the dynamics of ring current protons during a magnetic storm. We consider the case of the magnetic storm of October 21-22, 1999, considered by Ebihara et al. [11]. The initial time was 0613 UT of October 21, 1999, which corresponds to 0000 RT (Run Time - time of modeling) (magnetically quiet conditions). The time interval taken for calculations was 2030 RT (the final time - 0243 UT of October 22, 1999) (the main phase of the magnetic storm). At the initial time (0000 RT) $K p=2$ and then increases up to $K p=7+$. All model calculations were conducted for the nightside of the Earth's magnetosphere (2300 MLT) for protons with energy of $E=90 \mathrm{keV}$.

To accurately calculate the perpendicular $\left(\alpha=90^{\circ}\right)$ anisotropy index $\gamma_{\perp}$ of the pitch angle distribution of charged particles at any time, one should use the formula [3]

$$
\gamma_{\perp}=-\frac{1}{j_{\perp}}\left(\frac{d^{2} j}{d \alpha^{2}}\right)_{\perp}
$$

Or approximately this can be done if the second derivative $\left(\frac{d^{2} j}{d \alpha^{2}}\right)_{\perp}$ is determined with good accuracy from experimental data.

We approximate the initial pitch angle distribution of protons (0000 RT) by dependence (the data measured on the Polar/MICS satellite, in detail in [3] $L=5, \mathrm{MLT}=2300, E=90 \mathrm{keV}$ )

$$
j_{0}(\alpha)=j_{\perp 0} \sin ^{\gamma_{\perp 0}} \alpha \approx 36948 \sin ^{0.75} \alpha
$$

with the dimension $\left[j_{0}(\alpha)\right]=\left(\mathrm{cm}^{2} \mathrm{~s} \mathrm{sr} \mathrm{keV}\right)^{-1}$.

Before the storm, the pitch angle distribution is pancake-like but becomes butterfly-like in the main phase of the storm. The same tendency was noted by Ebihara et al. [11] and is in detail confirmed in [3].

The model proton fluxes were compared with the data measured on the Polar/MICS satellite during the magnetic storm of October 21-22, 1999. There is good agreement between simulated fluxes and experimental data [3].

Thus, the model PheMRC 2-D (1) quantitatively describes the model evolution of proton pitch angle distributions during the magnetic storm on October 21-22, 1999, which is associated with the concurrent effect of the physical mechanisms of radial diffusion, pitch angle diffusion, ,charge exchange, wave-particle interactions, splitting of drift shells of the electric field, and particle injection and drift.

Using the formula (2), dependence of a perpendicular $\left(\alpha=90^{\circ}\right)$ proton pitch angle distribution anisotropy index $\gamma_{\perp}$ with energy $E=90 \mathrm{keV}$ at the different moments of time (Fig. 1) from the McIlwain parameter $L(2.26 \leqslant L \leqslant 6.6)$ is received. It is certain at a quantitative level (Fig. 1) for the magnetic storm on October 21-22, 1999, when and where on the nightside of the Earth's magnetosphere (MLT $=2300)$ with increase in an geomagnetic activity $K p$-index there is a transition from normal or pancake-like proton pitch angle distributions $\left(\gamma_{\perp}>0\right)$ to butterfly-like proton pitch angle distributions $\left(\gamma_{\perp}<0\right)$.

At $\gamma_{\perp}=0$ the proton pitch angle distribution is isotropic. Therefore from figure 1 it is visible, that with increase in an geomagnetic activity $K p$-index the boundary of isotropic proton pitch angle distribution comes nearer to the Earth, reaching $L \approx 3.6$ at $K p=7+$. 


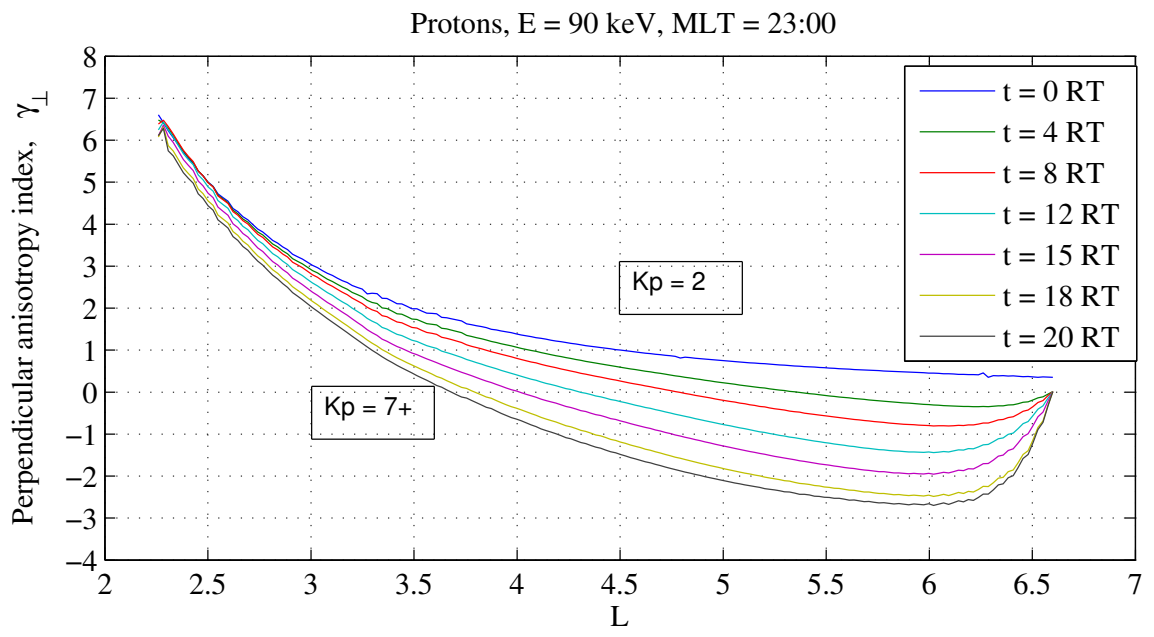

Fig. 1. Dependence of a perpendicular $\left(\alpha=90^{\circ}\right)$ proton pitch angle distribution anisotropy index $\gamma_{\perp}$ with energy $E=90 \mathrm{keV}$, MLT $=2300$ at the different moments of time from the McIlwain parameter $L(2.26 \leqslant L \leqslant 6.6)$ and the geomagnetic activity $K p$-index

Thus, the lead calculations have allowed to determine unequivocally and precisely the anisotropy dynamics of the proton pitch angle distribution in the given concrete case, using the proton pitch angle distribution anisotropy index for the pitch angle of 90 degrees $\gamma_{\perp}$ (Fig. 1).

\section{Conclusion}

1. The anisotropy dynamics of the ring current proton pitch angle distribution $(E=90 \mathrm{keV})$ in the inner Earth's magnetosphere $(2.26 \leqslant L \leqslant 6.6$, MLT $=2300)$ with variable boundary conditions during the magnetic storm of October 21-22, 1999, was investigated with the use of two-dimensional Phenomenological Model of the Ring Current (PheMRC 2-D) (1).

2. PheMRC 2-D takes into account the radial and pitch angle diffusions and describes the losses due to charge exchange and wave-particle interactions.

3. The model proton fluxes were compared with the data measured on the Polar/MICS satellite during the magnetic storm of October 21-22, 1999. There is good agreement between simulated fluxes and experimental data.

4. We confirmed the experimentally revealed tendency that the pitch angle distribution is pancake-like before the magnetic storm and that it becomes butterfly-like in the main phase of the storm.

5. With increase in an geomagnetic activity $K p$-index the boundary of isotropic proton pitch angle distribution comes nearer to the Earth, reaching $L \approx 3.6$ at $K p=7+$.

6. It is necessary to develop and specify in the further, for example, empirical (semiempirical) models of differential flux definition of charged particles at a pitch angle of $\alpha=90^{\circ} j_{\perp}$ and the anisotropy index of the pitch angle distribution of charged particles at a pitch angle of $\alpha=90^{\circ} \gamma_{\perp}$ under different geophysical conditions, especially for magnetically quiet conditions. 
7. With appropriate experimental data, the model PheMRC 2-D can be used to simulate the anisotropy dynamics of charged particles pitch angle distribution in the Jovian and Saturn magnetospheres.

\section{References}

[1] S.V.Smolin, Modeling of pitch angle distribution on the dayside of the Earth's magnetosphere, Journal of Siberian Federal University. Mathematics \& Physics, 5(2012), no. 2, 269-275 (in Russian).

[2] S.V.Smolin, Modeling the pitch angle distribution on the nightside of the Earth's magnetosphere, Geomagnetism and Aeronomy, 55(2015), no. 2, 166-173.

DOI: $10.1134 /$ S0016793215020152

[3] S.V.Smolin, Two-dimensional phenomenological model of ring current dynamics in the Earth's magnetosphere, Geomagnetism and Aeronomy, 59(2019), no. 1, 27-34.

DOI: $10.1134 /$ S0016793218040175

[4] X.Gu, Z.Zhao, B.Ni, Y.Shprits, C.Zhou, Statistical analysis of pitch angle distribution of radiation belt energetic electrons near the geostationary orbit: CRRES observations, $J$. Geophys. Res., 116(2011), A01208. DOI: 10.1029/2010JA016052

[5] J.E.Borovsky, M.H.Denton, A survey of the anisotropy of the outer electron radiation belt during high-speed-stream-driven storms, J. Geophys. Res., 116(2011), A05201.

DOI: 10.1029/2010JA016151

[6] Y.Chen, R.H.W.Friedel, M.G.Henderson, S.G.Claudepierre, S.K.Morley, H.Spence, REPAD: An empirical model of pitch angle distributions for energetic electrons in the Earth's outer radiation belt, J. Geophys. Res., 119(2014), 1693-1708. DOI: 10.1002/2013JA019431

[7] J.E.Borovsky, R.H.W.Friedel, M.H.Denton, Statistically measuring the amount of pitch angle scattering that energetic electrons undergo as they drift across the plasmaspheric drainage plume at geosynchronous orbit, J. Geophys. Res., 119(2014), 1814-1826.

DOI: $10.1002 / 2013 J A 019310$

[8] J.E.Borovsky, T.E.Cayton, M.H.Denton, R.D.Belian, R.A.Christensen, J.C.Ingraham, The proton and electron radiation belts at geosynchronous orbit: Statistics and behavior during high-speed stream-driven storms, J. Geophys. Res., 121(2016), 5449-5488.

DOI: $10.1002 / 2016 J A 022520$

[9] L.M.Kistler, C.G.Mouikis, The inner magnetosphere ion composition and local time distribution over a solar cycle, J. Geophys. Res., 121(2016), 2009-2032.

DOI: $10.1002 / 2015 J A 021883$

[10] H.Zhao, R.H.W.Friedel, Y.Chen, G.D.Reeves, D.N.Baker, X.Li, et al., An empirical model of radiation belt electron pitch angle distributions based on Van Allen probes measurements, J. Geophys. Res., 123(2018), 3493-3511. DOI: 10.1029/2018JA025277

[11] Y.Ebihara, M.-C.Fok, J.B.Blake, J.F.Fennell, Magnetic coupling of the ring current and the radiation belt, J. Geophys. Res., 113(2008), A07221. DOI: 10.1029/2008JA013267 


\title{
Моделирование динамики анизотропии питч-углового распределения протонов в магнитосфере Земли
}

Сергей В. Смолин

Сибирский федеральный университет Красноярск, Российская Федерация

\begin{abstract}
Аннотация. В последние годы внимание к исследованию анизотропии питч-углового распределения заряженных частиц значительно возросло. Поэтому для исследования динамики анизотропии питч-углового распределения протонов используется двумерная феноменологическая модель кольцевого тока PheMRC 2-D (two-dimensional Phenomenological Model of the Ring Current), которая включает радиальную и питч-угловую диффузии с учетом потерь вследствие взаимодействий волна-частица. Экспериментальные данные собраны на спутнике Polar/MICS во время магнитной бури 21-22 октября 1999 г. Решая нестационарное двумерное уравнение питч-угловой и радиальной диффузий, численно определяли индекс анизотропии питч-углового распределения протонов (или показатель питч-углового распределения протонов) для питч-угла 90 градусов во время магнитной бури, когда $K p$-индекс геомагнитной активности изменялся от 2 в начале бури до $7+$ в конце бури. Получена зависимость перпендикулярного индекса анизотропии питч-углового распределения протонов с энергией $E=90$ кэВ в разные моменты времени от параметра МакИлвейна $L(2.26<L<6.6)$. Определено на количественном уровне для магнитной бури $21-22$ октября 1999 г., когда и где на ночной стороне магнитосферы Земли (MLT $=2300)$ с увеличением $K p$ индекса геомагнитной активности имеется переход от нормальных (блиноподобных) питч-угловых распределений протонов к бабочкоподобным питч-угловым распределениям. Это позволило определить однозначно и точно динамику анизотропии питч-углового распределения протонов в данном конкретном случае. Показано, что с увеличением $K p$-индекса геомагнитной активности граница изотропного питч-углового распределения протонов приближается к Земле, достигая $L \approx 3.6$ при $K p=7+$.
\end{abstract}

Ключевые слова: магнитосфера, питч-угловое распределение, анизотропия, данные спутника Polar/MICS, поток протонов. 